\title{
Effects of Endothelin Receptor Antagonist on Cyclosporine-induced Vasoconstriction in Isolated Rat Renal Arterioles
}

\author{
Diane M. Lanese and John D. Conger \\ Department of Medicine, University of Colorado Health Sciences Center and Veterans Affairs Medical Center, Denver, Colorado 80220
}

\begin{abstract}
Recent evidence suggests that the potent constrictor peptide, endothelin (ET) has a mediating role in cyclosporine A (CsA)related renal vasoconstriction. However, the nature of the CsA-ET interaction and effect on the renal vasculature is uncertain. The purpose of the present study was twofold: $(a)$ to determine if CsA exposure caused direct local release of ET from the endothelium of the renal microvasculature and $(b)$ to determine if locally generated ET has paracrine effects on the underlying vascular smooth muscle to induce vasoconstriction. Experiments were performed in isolated rat renal arterioles. First it was determined that both afferent arteriole (AA) and efferent arteriole (EA) exhibited concentration-dependent decreases in lumen diameter to increasing molar concentrations of CsA. The AA was more sensitive to the vasoconstrictive effects of CsA than the EA. Next, the blocking effect of a recently synthesized putative $\mathrm{ET}_{\mathrm{A}}$ receptor antagonist was verified in both the AA and EA, where it was found that the cyclic peptide cyclo D-Asp-L-Pro-D-Val-L-Leu-D-Trp totally inhibited the vasoconstriction observed with ET addition. Finally, the role of locally stimulated ET in CsA-induced vasoconstriction was tested by determining the effect of the $\mathrm{ET}_{\mathrm{A}}$ receptor antagonist on CsA-induced AA and EA constriction. In the AA the vasoconstrictor effect of $10^{-11} \mathrm{M}$ CsA was completely blocked by the $\mathrm{ET}_{\mathrm{A}}$ receptor antagonist. However, in contrast to $\mathrm{AA}, 1^{-11}$ $M$ CsA in EA in the presence of the ET $_{A}$ receptor antagonist decreased $E A$ lumen diameter by a mean of $41 \%$ from baseline $(4.80 \pm 0.75 \mu \mathrm{m}$ vs $7.80 \pm 0.84 \mu \mathrm{m}, P<0.05)$. This change in lumen diameter was similar to that induced by $\mathrm{CsA}$ alone. These data suggest that $\mathrm{CsA}$ directly constricts renal microvessels. This effect is mediated by ET in the AA but not the EA. ( $J$. Clin. Invest. 1993. 91:2144-2149.) Key words: afferent • efferent $\bullet$ nephrotoxicity $\bullet$ vascular transplant
\end{abstract}

\section{Introduction}

Cyclosporine $\mathrm{A}(\mathrm{CsA})^{1}$ is an effective immunosuppressive agent; however, its clinical efficacy is complicated by substantial nephrotoxicity. The exact mechanism for CsA-induced nephrotoxicity is unclear, but a growing body of evidence sug-

Address correspondence to John D. Conger, M. D., Veterans Affairs Medical Center (111C), 1055 Clermont Street, Denver, CO 80220.

Received for publication 8 September 1992 and in revised form 30 November 1992.

1. Abbreviations used in this paper: $\mathrm{AA}$, afferent arteriole; $\mathrm{AII}$, angiotensin II; CsA, cyclosporine A; EA, efferent arteriole; ET, endothelin; ET$\mathrm{A}, \mathrm{ET}_{\mathrm{A}}$ receptor antagonist.

The Journal of Clinical Investigation, Inc.

Volume 91, May 1993, 2144-2149 gests that the primary pathogenetic mechanism may be vascular (1-3). The vascular effects of CsA in animal models have included sustained vasoconstriction in both the pre- and postglomerular circulation (4-9). While a direct effect has not been absolutely excluded, a number of physiologic agonists have been implicated as mediators of CsA-induced vasoconstriction. Recent evidence has supported a potentially important role for the potent constrictor peptide, endothelin (ET), in the effects of CsA on vascular smooth muscle (6). The exact role played by ET in CsA-induced vasoconstriction is uncertain. A number of investigators have demonstrated an increase in urinary ET excretion in rats after acute CsA infusion (10,11). The study of Bunchman et al. (12) showing concentration-dependent CsA induction of ET synthesis in cultured endothelial cells would indicate that CsA may directly stimulate increased ET activity in the systemic or renal vasculature. On the other hand, the findings of Zimmerhackl et al. (13) suggest that ET stimulation by CsA may be more complex. Using the hydronephrotic rat kidney, they showed that CsA-induced vasoconstriction was limited to the more proximal vessels, i.e., arcuate and interlobular arteries. Thus, it is possible that the proximal vasoconstrictor effect of CsA is either direct, or mediated by another agonist, and the increase in ET activity is secondary to distal arterial ischemia, a potent stimulus of ET release (14).

In addition to the question regarding the mechanism of stimulation, there is also uncertainty surrounding the mode and site of action of ET released by CsA exposure. Kon et al. (6) reported an attenuation of acute CsA-induced renal vasoconstriction and glomerular dysfunction with renal arterial infusion of rabbit anti-porcine endothelin antibody. Presumably, the molecular radius of such an antibody was too large to permit significant extravascular movement into the subintimal or perivascular space suggesting its primary effect likely involved the binding of circulating ET. On the other hand, there is evidence that ET released from endothelial cells acts primarily by a paracrine mechanism, binding to receptors on adjacent smooth muscle cells $(15,16)$. Theoretically, such a mechanism would not be affected by an anti-ET antibody with limited access to the subintimal space. Thus the extent to which CsAinduced ET acts by an immediate paracrine mechanism or by release into the circulation with subsequent binding to downstream smooth muscle cell receptors after gaining access to the perivascular and subendothelial spaces is unresolved.

The purpose of the present study was, first, to determine whether CsA exposure caused direct local release of ET from the endothelium of the renal microvasculature in either pre- or postglomerular resistance vessels and, second, to determine if locally generated ET could act in a paracrine fashion on the underlying vascular smooth muscle to induce vasoconstriction. The isolated renal arteriolar vessel technique was used to address these questions. As the initial step, CsA concentration related changes in afferent (AA) and efferent arteriolar (EA) lumen diameters were measured. Next, the effect of a new cy- 
clic pentapeptide $\mathrm{ET}_{\mathrm{A}}$ receptor antagonist on ET-1-induced $A A$ and EA vasoconstriction was determined (17). Finally, the effect of the $\mathrm{ET}_{\mathrm{A}}$ receptor antagonist on CsA-induced $\mathrm{AA}$ and EA constriction was assessed.

\section{Methods}

The in vitro-isolated rat arteriole technique used in these experiments has been described in detail previously $(18,19)$. Sprague-Dawley rats $(200-250 \mathrm{~g})$ that had been given standard rat chow and water ad lib. for 1 wk were anesthetized with methoxyflurane. The kidneys were removed through a midline abdominal incision and immediately place in a $4^{\circ} \mathrm{C}$ dissecting media of Krebs-Ringer bicarbonate buffer ( $\mathrm{pH} 7.4$ ) consisting of $(\mathrm{mM}) \mathrm{NaCl} 115, \mathrm{NaHCO}_{3} 25, \mathrm{~K}_{2} \mathrm{PO}_{4} 2.5, \mathrm{MgSO}_{4} 1.2$, $\mathrm{CaCl}_{2} 1.8$, glucose 5.5 , pyruvic acid 2.0 , and $1 \mathrm{~g} / \mathrm{dl}$ dialyzed BSA (fraction V; Sigma Immunochemicals, St. Louis, MO). The kidneys were decapsulated, bisected longitudinally, and the medulla removed. The tissue was minced to $1-3-\mathrm{mm}$ fragments. Glomeruli were isolated by a sieving technique and AA and EA attached to individual glomeruli were transferred with a siliconized Pasteur pipette to a temperature controlled chamber ( $1-\mathrm{ml} \mathrm{vol})$ on a microscope stage. The glomerular end of the arteriole was aspirated into a pipette with a flute-shaped tip so that the glomerulus was compressed as the diameter of the pipette narrowed. The microvessels were cannulated by aspirating the nonglomerular end into the tip of a holding micropipette and the lumen cannulated with an inner perfusing micropipette with a minimal internal diameter of $8.2 \mu \mathrm{m}$. Perfusing pipettes of smaller diameter have been found to have significant tip resistance invalidating pressure estimates (19). The intraluminal pressure of the vessel was then set at a predetermined value with a syringe connected through a pressure transducer (100Db; Statham Instruments, Oxnard, CA) and a series of stopcocks to the luminal perfusion pipette. Pressure was recorded on a recorder (Statham). The intraluminal pressure was set at $80 \mathrm{mmHg}$ for AA and $30 \mathrm{mmHg}$ for EA. When placed in the perfusion chamber under high power magnification $(\times 1,100) \mathrm{AA}$ and EA were readily distinguished by their appearance, which had been determined previously from isolated glomeruli found to have both arterioles attached. The identifying criteria were detailed in earlier publications $(18,19)$. The vessel was then perfused at $37^{\circ} \mathrm{C}$ for $30 \mathrm{~min}$ before experimental manipulations with a perfusate identical to the previously described dissecting medium. The bathing solution (referred to in this study as "standard" bathing medium) was also identical to the dissecting medium except that it did not contain albumin. Albumin in the bathing solution was found to promote bacterial growth, which caused deterioration of the vessels. All bathing solutions were gassed with $80 \% \mathrm{O}_{2} / 20 \% \mathrm{CO}_{2}$ for 30 min before use. The bathing solution was continuously pumped through the chamber at $1.0 \mathrm{ml} / \mathrm{min}$. During experiments water-saturated gas $\left(80 \% \mathrm{O}_{2} / 20 \% \mathrm{CO}_{2}\right)$ was gently blown over the surface of the chamber to maintain $\mathrm{pH}$ at 7.40 which was measured frequently with a microliter pH meter (Radiometer, Copenhagen, Denmark).

The arterioles were observed at the above magnification with the use of a microscope, an attached camera and video monitor. Lumen diameter was measured directly from the monitor screen at various points along the vessel. Repeated measurements were made at these same points. Means of the measurements were calculated. Experiments were recorded on videotape. The viability of the vessels was assessed by the appearance of the intact wall and response to known vasoconstrictor agonists of established potency for this technique such as angiotensin II (AII) and NE.

The following protocols were carried out: (a) Effects of CSA and Cs $A$ vehicle on $A A$ and EA. Control measurements of AA and EA lumen diameters were made at 1 -min intervals for $2 \mathrm{~min}$. The standard bath was quickly changed to a standard bath containing either a known molar concentration of CsA or an equivalent concentration of CsA vehicle $\left(\right.$ Cremophor $\left.^{\circledR}\right)$. Because of both the prolonged vasoconstrictor effect and potential toxicity of repeated and cumulative CsA exposure, each vessel was exposed to only a single molar concentration of CsA. Lumen diameter was measured after 2 and 4 min of incubation.

(b) Effects of ET antagonist on ET-induced vasoconstriction of $A A$ and $E A$. Concentration response curves to increasing molar concentrations of ET were previously determined by our laboratory (16). Using known near maximal concentrations of ET for AA $\left(10^{-10} \mathrm{M}\right)$ and EA $\left(10^{-11} \mathrm{M}\right)$, changes in lumen diameter with ET alone were compared to changes observed with ET in the presence of the putative $\mathrm{ET}_{\mathrm{A}}$ receptor antagonist (Cyclo D-Asp-L-Pro-D-Val-L-Leu-D-Trp; Peptides International Inc., Louisville, KY). The vasoconstrictor inhibiting effect of the $\mathrm{ET}_{\mathrm{A}}$ receptor antagonist was tested by adding an excess concentration of the antagonist to the bathing medium $\left(10^{-7} \mathrm{M}\right.$ in the AA and $10^{-6} \mathrm{M}$ in the EA) after baseline lumen diameters were measured. Since the $\mathrm{ET}_{\mathrm{A}}$ receptor antagonist had some agonist effect, a maximal concentration of the antagonist that caused a $<10 \%$ change in baseline lumen diameter was chosen. Lumen diameter was again measured 4 min after adding the antagonist. ET was then added in AA and EA at the same respective concentrations as cited above in the presence of the antagonist. Lumen diameter was again measured after 2 and 4 min of incubation. The bath was then exchanged several times with the standard bathing medium. As a postcontrol step to assure vessel viability and reactivity, near $\mathrm{EC}_{50} \mathrm{AII}\left(10^{-10} \mathrm{M}\right.$ in $\mathrm{AA}, 10^{-11}$ in $\left.\mathrm{EA}\right)$ was added to the bathing media and changes in vessel lumen diameters were measured. Like ET, the $\mathrm{ET}_{\mathrm{A}}$ receptor antagonist appeared to have a prolonged affinity for the receptor and, as a consequence, ET could not be used as a postcontrol vasoconstrictor.

(c) Effects of ET antagonist on CsA-induced vasoconstriction in AA and $E A$. AA and EA were bathed in standard media and baseline lumen diameters measured. The ET antagonist was added to the bathing medium at the respective concentrations for AA and EA given above. The vessels were allowed to incubate for $4 \mathrm{~min}$ and repeat lumen diameters measured. CsA $\left(10^{-11} \mathrm{M}\right.$ in AA and $10^{-11} \mathrm{M}$ in EA $)$ was added to the bathing medium in the presence of the ET antagonist and lumen diameters measured at 2 and $4 \mathrm{~min}$. If the vessel failed to constrict in response to the above experimental manipulation, then the bath was exchanged several times. After lumen diameter was determined to be stable by repeated measurements, AII was added to the bath and changes in vessel lumen diameter recorded to affirm vessel viability and reactivity.

Data analysis and calculations. Data are expressed as mean \pm SEM. Except for the CsA concentration-response curves, the data are presented as actual lumen diameters in micrometers. CsA concentrationresponse data were presented as percent constriction to establish $\mathrm{EC}_{50}$ and maximal constricting concentrations. Values for mean dose of the agent required to produce $50 \%$ of maximal contraction was defined as the $\mathrm{EC}_{50}$. Two methods can be used to calculate the $\mathrm{EC}_{50}$. The first method, recently reviewed by Meddings et al. (20), determines the $\mathrm{EC}_{50}$ from best-fit curve nonlinear regression analysis. The second method uses the means of the individual vessel dose response curve at $50 \%$ contraction. Both methods yielded numbers that were not different from the other. In this study the second method was used. Maximal constriction was considered to be that concentration at which there was no further decrease in lumen diameter with addition of the next higher log concentration. Maximal constriction in every vessel occurred at $<2 \mu \mathrm{m}$ absolute mean lumen diameter. Comparisons of sequential responses within a group were made by repeated measures ANOVA and Scheffe's method for individual comparisons (21). An unpaired $t$ test was used to compare changes in lumen diameter to similar experimental maneuvers in separate study groups and between AA and EA with the same experimental maneuvers. $P<0.05$ was considered statistically significant.

\section{Results}

Effects of CsA and CsA vehicle on $A A$ and EA. The CsA concentration response curves for the AA and EA are shown in Figs. 1 and 2, respectively. In both the AA and EA there was a 


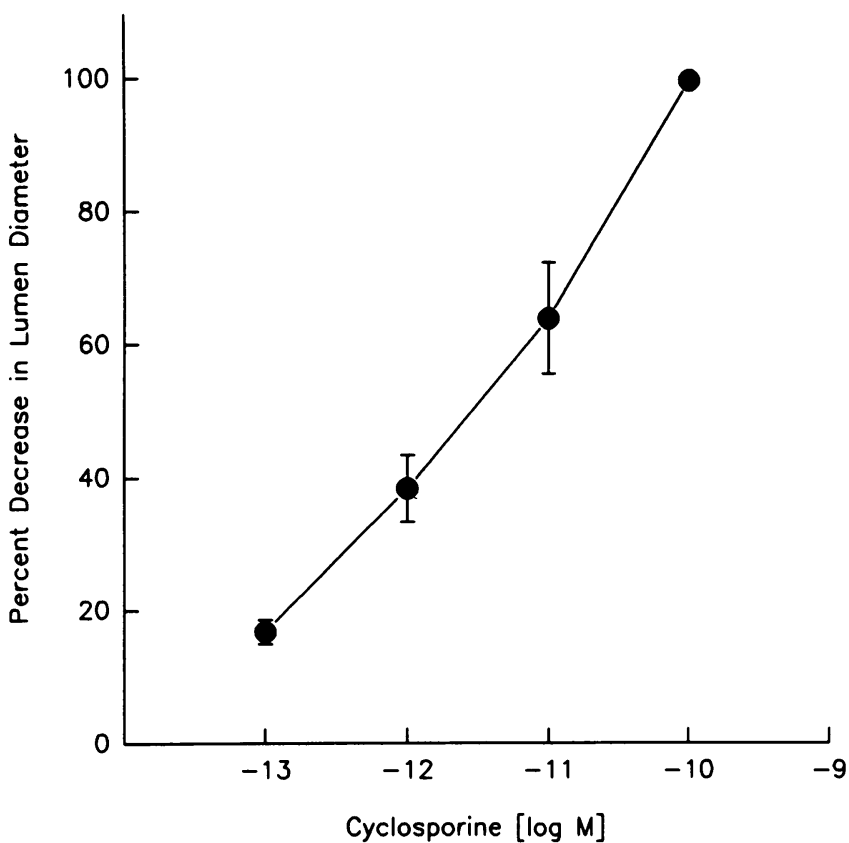

Figure 1. Cyclosporine concentration response curve in the AA ( $n$ $=20$ ). The data are presented as percent decrease in lumen diameter. There was a concentration dependent decrease in lumen diameter with increasing molar concentrations of CsA. The calculated $\mathrm{EC}_{50}$ value for $\mathrm{CsA}$ in the AA was $4.1 \pm 2.0 \times 10^{-12} \mathrm{M}$.

concentration-dependent decrease in lumen diameter with increasing molar concentrations of CsA. The calculated $\mathrm{EC}_{50}$ value for $\mathrm{CsA}$ in the $\mathrm{AA}(n=20)$ was $4.1 \pm 2.0 \times 10^{-12} \mathrm{M}$. The

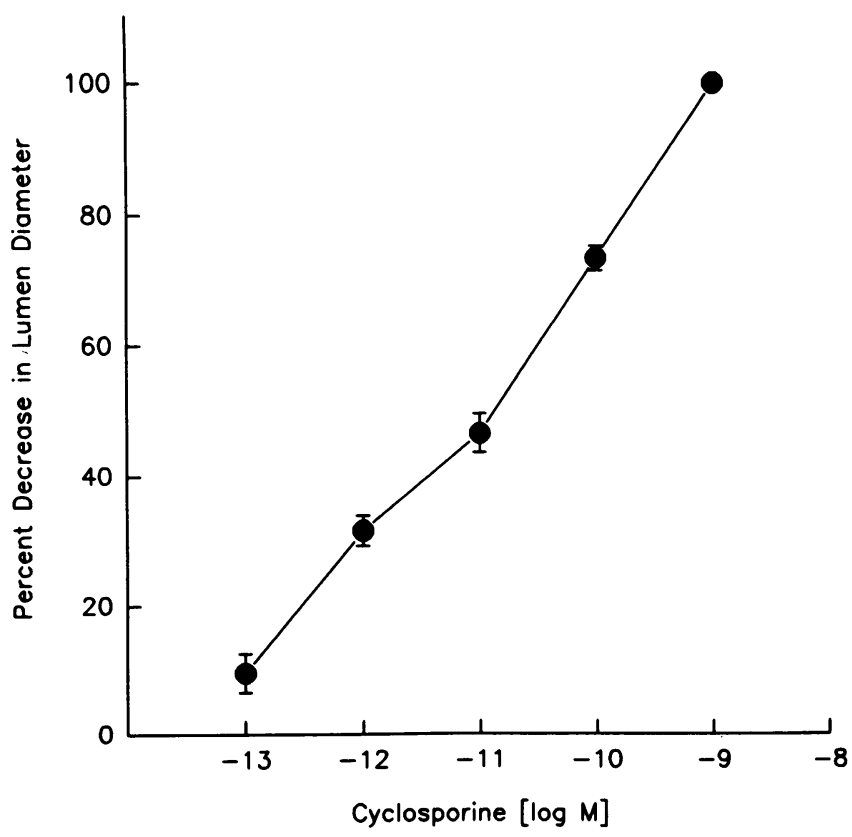

Figure 2. Cyclosporine concentration response curve in the EA ( $n$ $=24)$. The data are presented as percent decrease in lumen diameter. There was a concentration-dependent decrease in lumen diameter with increasing molar concentrations of CsA. The EA was less sensitive than the AA to the vasoconstrictive effects of CsA $(P<0.05)$. The calculated $\mathrm{EC}_{50}$ value was $3.1 \pm 0.7 \times 10^{-11} \mathrm{M}$.
EA $(n=24)$ was less sensitive than the AA to CsA with an $\mathrm{EC}_{50}$ value of $3.1 \pm 0.7 \times 10^{-11} \mathrm{M}(P<0.05)$. The CsA vehicle, applied in the diluent concentrations used with CsA in this study, had no effect on vessel lumen diameter in either the AA $(n=4)$ or EA $(n=4)$. Reactivity of these latter vessels was verified, however, by documenting their response to $\mathrm{EC}_{50} \mathrm{AII}$.

Effects of the ET antagonist on ET-induced vasoconstriction of $A A$ and $E A$. The data for AA and EA, respectively, are shown in Figs. 3 and 4. The mean lumen diameter of the AA before the addition of ET alone was $11.12 \pm 1.26 \mu \mathrm{m}$. Addition of $10^{-10} \mathrm{M}$ ET resulted in a marked decrease in lumen diameter to $2.75 \pm 1.60 \mu \mathrm{m}(P<0.05)$. When the $\mathrm{ET}_{\mathrm{A}}$ receptor antagonist was added to a separate group of $\mathrm{AA}(n=4)$, mean baseline lumen diameter did not change $(11.12 \pm 0.43$ vs $10.37 \pm 0.47 \mu \mathrm{m})$ and remained stable over $4 \mathrm{~min}$. When ET was then added in the presence of the antagonist, no further change in mean lumen diameter occurred $(10.37 \pm 0.47$ vs $10.37 \pm 0.51 \mu \mathrm{m})$. To determine vessel viability and reactivity, AII $\left(10^{-10} \mathrm{M}\right)$ was added to the bathing media after several bath exchanges. Mean lumen diameter decreased to $4.00 \pm 1.47$ $\mu \mathrm{m}(P<0.05)$.

Qualitatively similar results were seen in the EA. Baseline lumen diameter before ET $\left(10^{-11} \mathrm{M}\right)$ addition was $10.00 \pm 2.30$ $\mu \mathrm{m}(n=4)$. Addition of ET resulted in a significant decrease in lumen diameter to $3.25 \pm 1.70 \mu \mathrm{m}(P<0.05)$. In a separate group of EA in which the $\mathrm{ET}_{\mathrm{A}}$ receptor antagonist was added first, the mean baseline lumen diameter was $10.17 \pm 0.54 \mu \mathrm{m}(n$ $=6$ ). There was no significant change in mean baseline lumen diameter with addition of the ET antagonist (10.17 \pm 0.54 vs $9.58 \pm 0.64 \mu \mathrm{m})$. When ET was then added in the presence of the antagonist, ET-induced vasoconstriction was completely inhibited $(9.58 \pm 0.64$ vs $9.34 \pm 0.69 \mu \mathrm{m})$. Vessel viability was

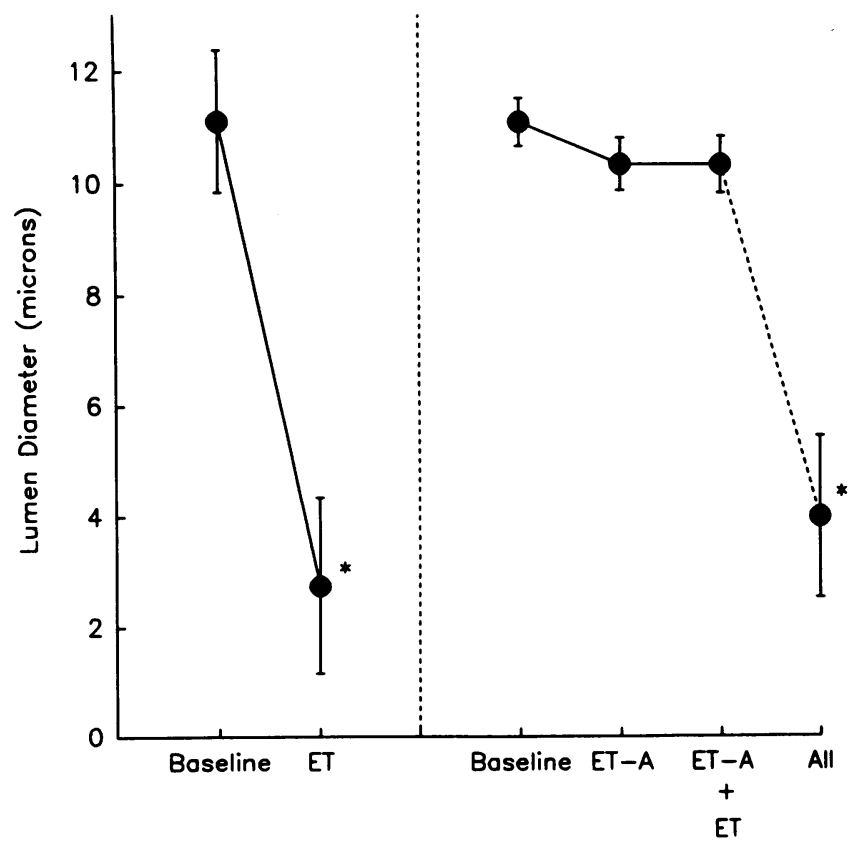

Figure 3. Effects of $10^{-10} \mathrm{M}$ ET alone and in the presence of ET-A in the AA. The left side of the graph represents changes in lumen diameter $(\mu \mathrm{m})$ with ET alone. (Right side) No significant change in lumen diameter was seen with addition of ET in the presence of ET-A. Subsequent AII addition resulted in a decrease in lumen diameter $\left(10.37 \pm 0.47\right.$ vs $\left.4.00 \pm 1.47 \mu \mathrm{m},{ }^{*} P<0.05\right)$. 


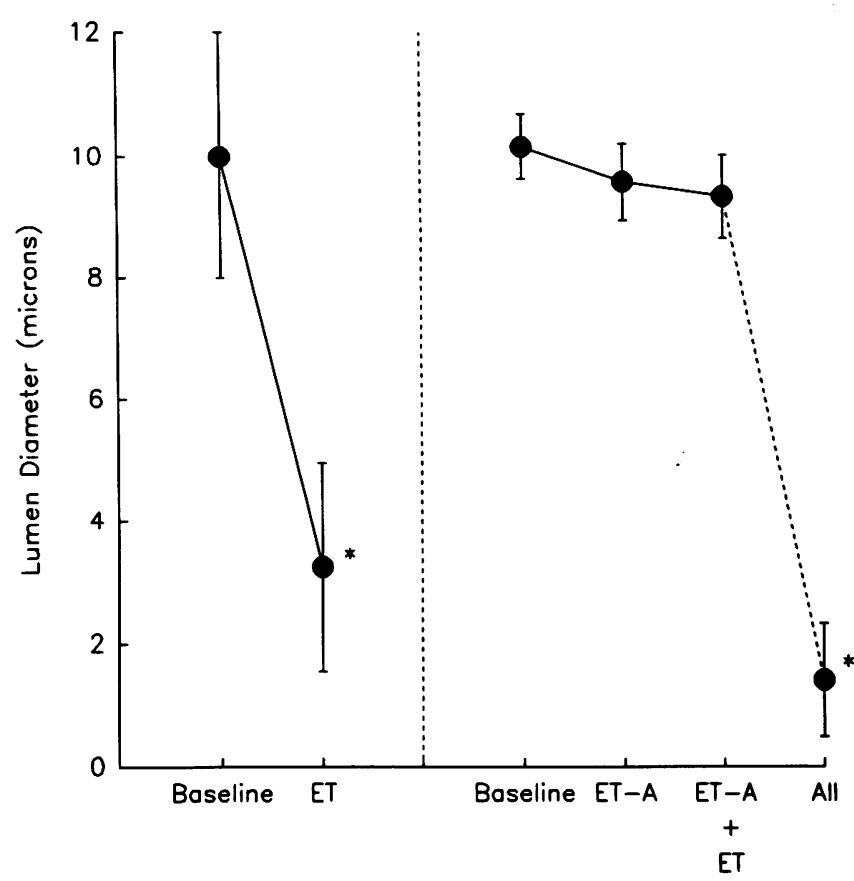

Figure 4. Effects of $10^{-11} \mathrm{M} \mathrm{ET}$ alone and in the presence of ET-A in the EA. The left side of the graph represents changes in lumen diameter $(\mu \mathrm{m})$ with ET alone. As in the AA, the EA showed no change in lumen diameter with ET in the presence of ET-A. AII caused a decrease in lumen diameter from a baseline of $9.34 \pm 0.69 \mu \mathrm{m}$ to $1.41 \pm 0.92 \mu \mathrm{m}\left({ }^{*} P<0.05\right)$.

confirmed with AII $\left(10^{-11} \mathrm{M}\right)$ which decreased mean lumen diameter to $1.41 \pm 0.92 \mu \mathrm{m}(P<0.05)$.

Effects of the ET antagonist on CSA-induced vasoconstriction in the $A A$ and $E A$. Data are presented in Figs. 5 and 6. Mean baseline lumen diameter in the AA $(n=6)$ was $13.42 \pm 2.23 \mu \mathrm{m}$. No significant reduction in lumen diameter occurred with addition of the ET antagonist ( $12.75 \pm 2.12 \mu \mathrm{m})$. A concentration of CsA $\left(10^{-11} \mathrm{M}\right)$ that caused a $64 \pm 8 \%$ decrease in AA lumen diameter when added alone, produced no change in lumen diameter when added in the presence of the ET antagonist $(13.33 \pm 2.28 \mu \mathrm{m})$. However, AII added to the bathing medium decreased lumen diameter to $4.75 \pm 2.37 \mu \mathrm{m}$ $(P<0.05)$.

Results in EA contrasted sharply from those observed in AA. Baseline lumen diameter of EA $(n=5)$ was $8.20 \pm 1.68 \mu \mathrm{m}$. Addition of the ET antagonist alone resulted in an insignificant decrease in lumen diameter $(7.80 \pm 0.84 \mu \mathrm{m})$. When $10^{-11} \mathrm{M}$ CsA was then added in the presence of the ET antagonist, mean lumen diameter decreased by $41 \pm 10 \%$ to $4.80 \pm 0.75 \mu \mathrm{m}(P$ $<0.05$ ). This change in lumen diameter was not different from the change in lumen diameter that occurred with CsA alone (Fig. 2).

\section{Discussion}

The present study demonstrated that in isolated resistance arterial vessels, devoid of systemic and renal parenchymal neurohumoral influences, CsA caused a concentration-dependent constrictor effect. Cyclosporine A vasoconstriction in the AA required the mediation of $\mathrm{ET}_{\mathrm{A}}$ receptor activation by assumed CsA-stimulated synthesis and release of ET. Constriction of EA by CsA, on the other hand, did not require ET-ET ${ }_{\mathrm{A}}$ interaction.

The results of this study, in part, confirm the in vivo findings of Kon et al. (6) which showed that infusion of an ET antibody attenuated the renal vasopressor effects of CsA. In addition, an in vitro study by Takeda et al. (17) demonstrated that the $\mathrm{ET}_{\mathrm{A}}$ receptor antagonist blocked CsA-induced myosin light chain phosphorylation, a biochemical assessment of mesangial cell contraction in culture. However, the model and design of the current study permitted examination of additional specific questions regarding cyclosporine A's vascular effects and the nature of the mediating role of ET. These questions included the site of vascular action of CsA, the potential importance of ischemia in CsA-induced ET release, the possibility of a direct paracrine effect of CsA-stimulated ET on adjacent vascular smooth muscle cells and the importance of ET mediation in pre- and postglomerular arterial vessels.

While the data of this study do not address the constrictor response of more proximal renal arterial vessels to CsA, they clearly show that the immediate juxtaglomerular vasculature is directly responsive to CsA at concentrations that are at least an order of magnitude lower than the generally accepted plasma therapeutic range in renal transplant patients (22). These results differ from those of Zimmerhackl (13) who showed arcuate and interlobular artery, but not arteriolar, constriction with CsA infusion in the hydronephrotic rat kidney. It is possible that there was a reactive autoregulatory vasodilatation of the more distal vasculature associated with constriction of arcuate and interlobular arteries in the intact kidney that obscured a direct or mediated constrictor effect of CsA. The pres-

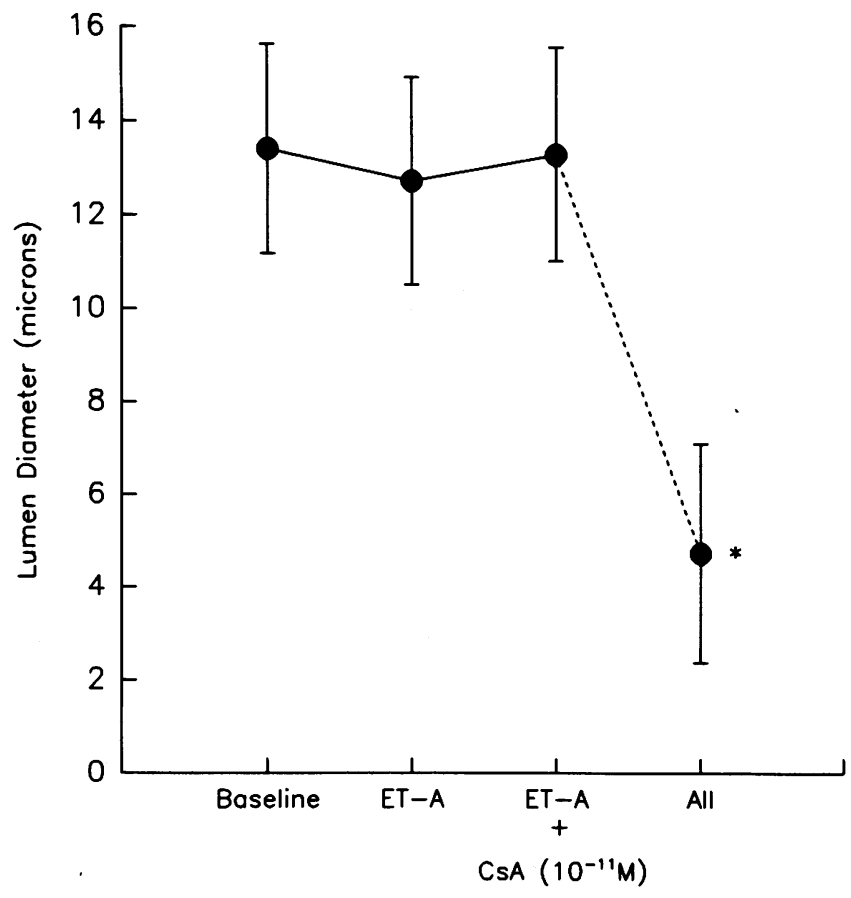

Figure 5. Cyclosporine $\left(10^{-11} \mathrm{M}\right)$ and ET-A in the AA. Baseline lumen diameter was $13.42 \pm 2.23 \mu \mathrm{m}$, which did not change with addition of the ET-A. In contrast to the response to CsA alone, addition of $10^{-11} \mathrm{M}$ CsA in the presence of the ET antagonist did not result in a decrease in lumen diameter. However, AII added to the bath decreased lumen diameter to $4.75 \pm 2.37 \mu \mathrm{m} .{ }^{*} P<0.05$. 


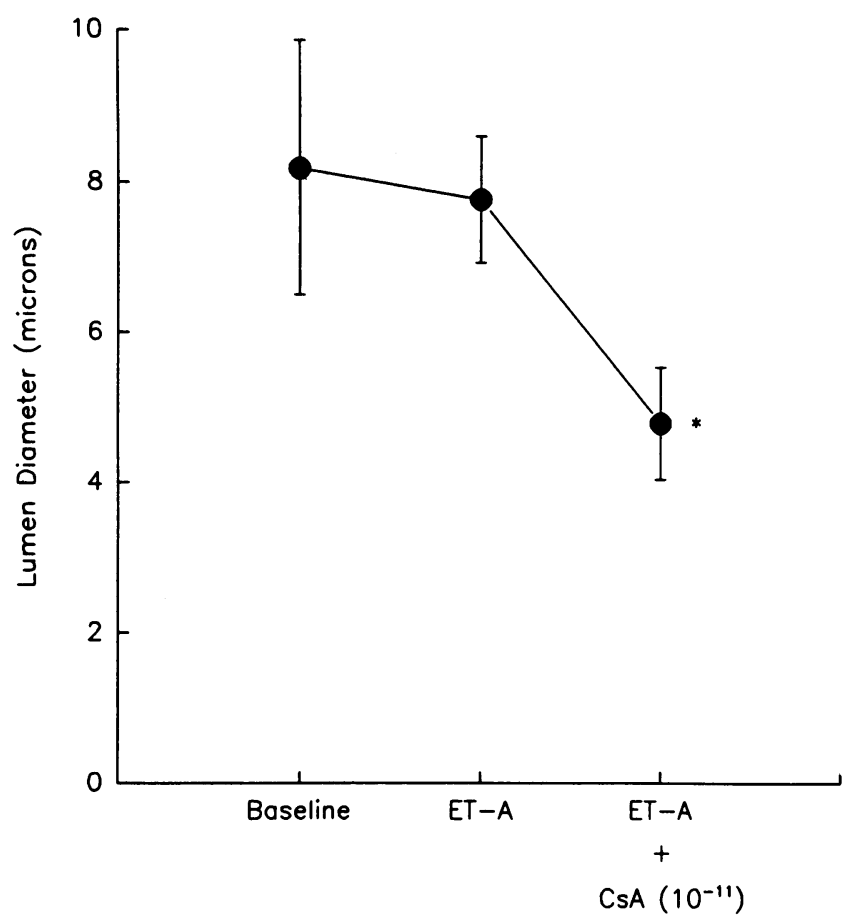

Figure 6. Cyclosporine $\left(10^{-11} \mathrm{M}\right)$ and ET-A in the EA. Lumen diameter remained stable with addition of the ET-A. Addition of $10^{-11}$ $M$ CsA resulted in a decrease in lumen diameter to $4.8 \pm 0.75 \mu \mathrm{m}\left({ }^{*} P\right.$ $<0.05$ ), a decline similar to that found with CsA alone.

ent study cannot exclude such a possibility. However, the study of Kon et al. (6) showing changes in efferent, in addition to afferent, arteriolar resistance with intravenous CsA infusion in a micropuncture study would support the importance of direct arteriolar effects of CsA in the in vivo setting.

The possibility that ischemia may have stimulated ET release with exposure to CsA was suggested by the finding of proximal arterial constriction in the study by Zimmerhackl (13). ET release and increases detected in the urine could have come from the endothelium of the distal renal vasculature as the consequence of reduced perfusion. Ischemia is a known potent stimulus of ET release $(14,23)$. The present findings do not support such a mechanism. Rather, they indicate that CsA's stimulation of endothelin occurs directly without interposed ischemia. The isolated vessel system is adequately oxygenated and not part of a more complex vascular network. Thus, the indirect evidence of ET stimulation with the $\mathrm{ET}_{\mathrm{A}}$ receptor antagonist, particularly in AA, would indicate that ischemia is not an important element of CsA-induced ET activity. The finding of increased immunoreactive ET in the supernatant of cultured endothelial cells exposed to CsA (12) also would support the direct ET stimulation of CsA.

The relative roles of cumulative circulating ET and the paracrine effect of locally generated ET in the vasoconstrictor effect of CsA, at least in the AA, were not directly determined in this study. However, the finding of complete inhibition of the CsAinduced response using a low molecular weight $\mathrm{ET}_{\mathrm{A}}$ receptor blocker in an isolated vessel with negligible luminal flow would suggest that the paracrine effect of ET is substantial. Thus, while the ET antibody results reported by Kon et al. (6) would argue that circulating ET attenuation modifies the vasoconstrictor effect of CsA, the effect of adjacent endothelial ET on underlying smooth muscle likely contributes significantly to the increased resistance of the small renal arterial vasculature.

The failure of $\mathrm{ET}_{\mathrm{A}}$ blockade to inhibit the constrictor effect of CsA in EA, as opposed to AA, was not anticipated. The preliminary studies showing that the $\mathrm{ET}_{\mathrm{A}}$ receptor antagonist at the concentration used completely blocked the effect of a near maximal constricting concentration of exogenously added ET in efferent arterioles would indicate that the $\mathrm{ET}_{\mathrm{A}}$ receptor inhibition was pharmacologically effective and adequate. Therefore, it is likely that there is either a direct effect of CsA in the EA that does not require ET, or CsA stimulates another mediating agent in this vessel. It is interesting to note the results with ET antibody in the micropuncture study of Kon et al. (6) suggested that the ET-mediating role of CsA vasoconstriction might have been different in AA and EA. The reduction in afferent arteriolar resistance with ET antibody infusion was, in fact, twofold greater than the observed decline in efferent arteriolar resistance suggesting that antagonism of ET had a greater impact on CsA-induced tone in AA. Other physiologic agonists have been implicated in the renal vasoconstrictor effects of CsA including AII, catecholamines, platelet-activating factor, and thromboxane $A_{2}(7,24-29)$. Additional experiments will be required to determine mediated and direct effects of CsA in the postglomerular vasculature:

\section{Acknowledgments}

These studies were supported by National Institute of Diabetes, Digestive and Kidney Diseases grant RO1 DK41294, and National Research Service award 5 S32 DK 08611-02.

\section{References}

1. Schnabel, F. R., R. B. Wait, P. Aaronson, and K. U. Kahng. 1989. Effect of cyclosporine A administration on vascular reactivity in the rabbit. Transplant. Proc. 21:918-921.

2. Bossaller, C., U. Forstermann, R. Hertel, C. Olbricht, V. Reschke, and E. Fleck. 1989. Cyclosporin A inhibits endothelium-dependent vasodilatation and vascular prostacyclin production. Eur. J. Pharmacol. 165:165-169.

3. Rego, A., R. Vargas, M. L. Foegh, and P. W. Ramwell. 1988. Effect of cyclosporine A treatment on vascular reactivity of the rat thoracic aorta. Transplant. Proc. 20:572-577.

4. Curtis, J. J., and S. A. Laskow. 1988. Cyclosporine-induced nephrotoxicity: pathophysiology of decreased blood flow. Transplant. Proc. 20:540-543.

5. Sullivan, B. A., L. J. Hak, and W. F. Finn. 1985. Cyclosporine nephrotoxicity: studies in laboratory animals. Transplant. Proc. 17:145-154.

6. Kon, V., M. Sugiura, T. Inagami, B. R. Harvie, I. Ichikawa, and R. L. Hoover. 1990. Role of endothelin in cyclosporine-induced glomerular dysfunction. Kidney Int. 37:1487-1491.

7. Barros, E. J., M. A. Boim, H. Ajzen, O. L. Ramos, and N. Schor. 1987. Glomerular hemodynamics and hormonal participation on cyclosporine nephrotoxicity. Kidney Int. 32:19-25.

8. Kaskel, F. J., P. Devarajan, L. A. Arbeit, and L. C. Moore. 1988. Effects of cyclosporine on renal hemodynamics and autoregulation in rats. Transplant. Proc. 20:603-609.

9. Murray, B. M., M. S. Paller, and T. F. Ferris. 1985. Effect of cyclosporine administration on renal hemodynamics in conscious rats. Kidney Int. 28:767774.

10. Brooks, D. P., E. H. Ohlstein, L. C. Contino, B. Storer, M. Pullen, M. Caltabiano, and P. Nambi. 1991. Effect of nifedipine on cyclosporine A-induced nephrotoxicity, urinary endothelin excretion and renal endothelin receptor number. Eur. J. Pharmacol. 194:115-117.

11. Nambi, P., M. Pullen, L. C. Contino, and D. P. Brooks. 1990. Upregulation of renal endothelin receptors in rats with cyclosporine A-induced nephrotoxicity. Eur. J. Pharmacol. 187:113-116.

12. Bunchman, T. E., and C. A. Brookshire. 1991. Cyclosporine-induced synthesis of endothelin by cultured human endothelial cells. J. Clin. Invest. 88:310-314.

13. Zimmerhackl, L. B., M. Fretschner, and M. Steinhausen. 1990. Cyclosporine reduces renal blood flow through vasoconstriction of arcuate arteries in the hydronephrotic rat model. Klin. Wochenschr. 68:166-174. 
14. Rakugi, H., Y. Tabuchi, M. Nakamaru, M. Nagano, K. Higashimori, H. Mikami, T. Ogihara, and N. Suzuki. 1990. Evidence for endothelin-1 release from resistance vessels of rats in response to hypoxia. Biochem. Biophys. Res. Commun. 169:973-977.

15. Luscher, T. F., H. A. Bock, Z. Yang, and D. Diederich. 1991. Endothelium-derived relaxing and contracting factors: perspectives in nephrology. Kidney Int. 39:575-590.

16. Lanese, D. M., B. H. Yuan, I. F. McMurtry, and J. D. Conger. 1992. Comparative sensitivities of isolated rat renal arteries to endothelin. Am. J. Physiol. 263:F894-899.

17. Takeda, M., M. D. Breyer, T. D. Noland, T. Homma, R. L. Hoover, T. Inagami, and V. Kon. 1992. Endothelin-1 receptor antagonist: effects on endothelin- and cyclosporine-treated mesangial cells. Kidney Int. 42:1713-1719.

18. Yuan, B. H., J. B. Robinette, and J. D. Conger. 1990. Effect of angiotensin II and norepinephrine on isolated rat afferent and efferent arterioles. $\mathrm{Am}$. J. Physiol. 258:F741-750.

19. Lanese, D. M., B. H. Yuan, S. A. Falk, and J. D. Conger. 1991. The effects of AP-III on the isolated afferent and efferent arterioles of the rat kidney. Am. J. Physiol. 261:F1102-1109.

20. Meddings, J. B., R. B. Scott, and G. H. Fick. 1989. Analysis and comparison of sigmoidal curves: application to dose-response data. Am. J. Physiol. 257:G982-989.

21. Wallenstein, S., C. L. Zucker, and J. L. Fleiss. 1980. Some statistical methods useful in circulation research. Circ. Res. 47:1-9.
22. Frey, F. J. 1991. Pharmacokinetic determinants of cyclosporine and prednisone in renal transplant patients. Kidney Int. 39:1034-1050.

23. Randall, M. D. 1991. Vascular activities of the endothelins. Pharmacol. Ther. 50:73-93.

24. Moss, N. G., S. L. Powell, and R. J. Falk. 1985. Intravenous cyclosporine activates afferent and efferent renal nerves and causes sodium retention in innervated kidneys in rats. Proc. Soc. Natl. Acad. Sci. USA. 82:8222-8226.

25. Rodriquez-Puyol, D., S. Lamas, A. Olivera, A. Lopez-Farre, G. Ortega, L. Hernando, and J. M. Lopez-Novoa. 1989. Actions of cyclosporine A on cultured rat mesangial cells. Kidney Int. 35:632-637.

26. Pavao dos Santos, O. F., M. A. Boim, R. Bregman, S. A. Draibe, E. J. G. Barros, E. Pirotzky, N. Schor, and P. Braquet. 1989. Effect of platelet-activating factor antagonist on cyclosporine nephrotoxicity. Transplantation (Baltimore). 47:592-595.

27. Kho, T. L., K. M. L. Leunissen, P. L. Heidendahl, P. Lijnen, A. Amery, and J. P. van Hooff. 1988. Cyclosporine and urinary prostaglandins. Transplant. Proc. 20:650-653.

28. Smeesters, C., P. Chaland, L. Giroux, J. M. Moutquin, P. Etienne, F. Douglas, J. Corman, G. St.-Louis, and P. Daloze. 1988. Prevention of acute cyclosporine A nephrotoxicity by a thromboxane synthetase inhibitor. Transplant. Proc. 20:658-664.

29. Perico, N., M. Rossini, O. Imberti, B. Malanchini, R. P. Cornejo, F. Gaspari, T. Bertani, and G. Remuzzi. 1992. Thromboxane receptor blockade attenuates chronic cyclosporine nephrotoxicity and improves survival in rats with renal isograft. J. Am. Soc. Nephrol. 2:1398-1404. 